\title{
RpoE2 of Sinorhizobium meliloti is necessary for trehalose synthesis and growth in hyperosmotic media
}

\author{
Maud Flechard, Catherine Fontenelle, Carlos Blanco, Renan Goude, \\ Gwennola Ermel and Annie Trautwetter
}

Correspondence

Annie Trautwetter

annie.trautwetter@univ-rennes1.fr

Received 17 September 2009

Revised 4 February 2010

Accepted 8 March 2010

\author{
UMR CNRS 6026, DUALS, Université de Rennes I, Campus de Beaulieu, Av. du Général Leclerc, \\ 35042 Rennes, France
}

\begin{abstract}
Adaptation to osmotic stress can be achieved by the accumulation of compatible solutes that aid in turgor maintenance and macromolecule stabilization. The genetic regulation of solute accumulation is poorly understood, and has been described well at the molecular level only in enterobacteria. In this study, we show the importance of the alternative sigma factor RpoE2 in Sinorhizobium meliloti osmoadaptation. Construction and characterization of an S. meliloti rpoE2 mutant revealed compromised growth in hyperosmotic media. This defect was due to the lack of trehalose, a minor carbohydrate osmolyte normally produced in the initial stages of growth and in stationary phase. We demonstrate here that all three trehalose synthesis pathways are RpoE2 dependent, but only the OtsA pathway is important for osmoinducible trehalose synthesis. Furthermore, we confirm that the absence of RpoE2-dependent induction of ots $A$ is the cause of the osmotic phenotype of the rpoE2 mutant. In conclusion, we have highlighted that, despite its low level, trehalose is a crucial compatible solute in S. meliloti, and the OtsA pathway induced by RpoE2 is needed for its accumulation under hyperosmotic conditions.
\end{abstract}

\section{INTRODUCTION}

Living cells adapt to an increase of external osmolarity by accumulating organic osmolytes in the cytoplasm. These compounds are accumulated at high intracellular concentration, and they allow turgor recovery. Indeed, their presence at high intracellular concentration must not be deleterious for metabolism. So, only members of a limited number of families of molecules are used as organic osmolytes by living cells (Yancey et al., 1982). These osmolytes are members of the polyols, amino acids (and their derivatives) and quaternary ammonium amines (da Costa et al., 1998). These compounds are synthesized by osmotically stressed cells, and hereafter they are referred to as endogenous osmolytes. Bacteria synthesize one or various endogenous osmolytes (Roessler \& Müller, 2001). If present in the surrounding medium, osmolytes can also be accumulated by active transport (Sleator \& Hill, 2002), and these are called osmoprotectants.

In addition to their contribution to turgor recovery, organic osmolytes have other roles in the cell (Yancey,

Abbreviations: ABTS, azino-bis(3-ethylbenzothiazoline-6-sulfonic acid); $\mathrm{HB}$, homobetaine; LB, Luria-Bertani; NAGGN, N-acetylglutaminylglutamine amide.

A supplementary figure showing the localization and nucleotide sequence of DNA fragments used for the promoter assays is available with the online version of this paper.
2005). They are, in some instances, called chemical chaperones, since they have a similar action to genuine chaperones, both in vitro and in vivo (Bourot et al., 2000; Crowe, 2007; Diamant et al., 2001). Osmolytes are also active cytoprotectants (Singer \& Lindquist, 1998; Yancey, 2005). When various osmolytes are present within the cell, it is difficult to understand their specific roles; some might be involved in turgor maintenance only, while others might have a minor effect on turgor but a great effect on macromolecular protection (Crowe, 2007; Yancey, 2005).

Adaptation of Sinorhizobium meliloti to an increase in medium osmolarity is achieved by the accumulation of three organic osmolytes: glutamate and the dipeptide $\mathrm{N}$-acetylglutaminylglutamine amide (NAGGN) are the main solutes present during the exponential growth phase (Smith \& Smith, 1989), and trehalose has been described as a minor osmolyte present during the exponential growth phase, but its concentration increases at the end of exponential growth (Gouffi et al., 1999). Osmoprotectants glycine betaine (Talibart et al., 1997), homobetaine (HB) (Barra et al., 2006) and dimethylsulfoniopropionate (Pichereau et al., 1998) are accumulated within the cell to act as substitutes for endogenous osmolytes. In contrast with other bacteria, some osmoprotectants, such as ectoine (Talibart et al., 1994), and disaccharides, such as sucrose (Gouffi et al., 1999), exert a strong osmoprotective effect, while they are never accumulated. In S. meliloti, these non-accumulated compounds 
allow a strong increase of glutamate and NAGGN synthesis, while they do not affect the trehalose level.

In bacteria, three major pathways of trehalose synthesis have been described (De Smet et al., 2000; Wolf et al., 2003). Trehalose-6-phosphate synthase (OtsA) allows the conversion of UDP-glucose and glucose-6-phosphate into trehalose-6-phosphate, which is dephosphorylated in a second step by trehalose-6-phosphate phosphatase (OtsB). Trehalose can also be synthesized from malto-oligosaccharides by a mechanism involving two enzymes: maltooligosyl trehalose synthase (TreY), which converts $\alpha(1 \rightarrow 4)$ bonds of reducing extremities of maltodextrins into $\alpha(1 \rightarrow 1)$ bonds, and malto-oligosyl trehalose trehalohydrolase (TreZ), which cleaves the resulting terminal trehalose moiety. Finally, trehalose synthase (TreS) catalyses the conversion of maltose into trehalose, and is also able to function in the opposite direction according to stoichiometric conditions (Cardoso et al., 2007). The regulation of trehalose synthesis is RpoSdependent in Escherichia coli (Hengge-Aronis et al., 1991) and Salmonella typhimurium (Fang et al., 1996), but the regulatory mechanisms controlling its synthesis have not been identified in other bacteria.

In S. meliloti, enzymic activities corresponding to TreYZ pathways have been described in strains 102F34, 1005 and 1011 (Streeter \& Bhagwat, 1999). OtsAB activity has been described in GR4 strain (Streeter \& Gomez, 2006), but the corresponding genes and their regulation have not been characterized. The RpoS factor is absent in S. meliloti (Galibert et al., 2001), suggesting that other factors control trehalose synthesis in this bacterium. This regulation could be performed by RpoE factors. rpoE2, one of the 11 predicted rpoE genes (Galibert et al., 2001), was proposed as a general stress-response regulator when 44 RpoE2dependent genes were identified by a transcriptomic analysis (Sauviac et al., 2007). Moreover, rpoE2 is induced by osmotic stress (Sauviac et al., 2007), and this suggests that it could be involved in osmotic adaptation.

In this study, we observed a growth defect for an rpoE2 strain under salt stress, and showed that this defect resulted from the involvement of rpoE2 in the synthesis of the compatible solute trehalose.

\section{METHODS}

Bacterial strains and media. S. meliloti and E. coli strains are listed in Table 1; these were grown in Luria-Bertani (LB) medium (Miller, 1972). S. meliloti was also grown in GAS medium, which consists of $S$ medium (Gouffi et al., 1999) supplemented with $10 \mathrm{mM}$ galactose and $10 \mathrm{mM}$ aspartate, as carbon and nitrogen sources, respectively. Cells grown in LB were harvested, washed in minimal medium (S medium), and inoculated at an $\mathrm{OD}_{570}$ of 0.1. Osmoprotectants were added at a final concentration of $1 \mathrm{mM}$. S. meliloti and E. coli strains were grown aerobically at 30 and $37{ }^{\circ} \mathrm{C}$, respectively. When appropriate, antibiotics were added: neomycin $\left(50 \mu \mathrm{g} \mathrm{ml}^{-1}\right)$, gentamicin $\left(5 \mu \mathrm{g} \mathrm{ml}^{-1}\right)$ and tetracycline $\left(10 \mu \mathrm{g} \mathrm{ml}^{-1}\right)$ for E. coli, and neomycin $\left(50 \mu \mathrm{g} \mathrm{ml}^{-1}\right)$, gentamicin $\left(25 \mu \mathrm{g} \mathrm{ml}^{-1}\right)$ and tetracycline $\left(5 \mu \mathrm{g} \mathrm{ml}^{-1}\right)$ for S. meliloti.
DNA manipulations. Chromosomal and plasmid DNA isolations were carried out according to standard procedures (Sambrook et al., 1989). All cloning steps were performed in E. coli DH5 $\alpha$.

Inactivation of trehalose biosynthesis genes. A DNA fragment bearing ots $A$ or treY was amplified by PCR from Rm1021 genomic DNA using the oligonucleotides described in Table 2, and cloned into the pGEM-T Easy vector (Promega). An antibiotic resistance cassette $\left(\mathrm{Tc}^{\mathrm{R}}\right.$ and $\mathrm{Gm}^{\mathrm{R}}$ for otsA and treY, respectively) was introduced in a unique restriction site (EcoRI and SmaI for otsA and treY, respectively) of the target gene, and the mutated gene was transferred into $\mathrm{pK} 18 \mathrm{mobsacB}$. The recombinant suicide plasmid was introduced into the Rm1021 recipient strain by triparental mating, using strain MT616 for its mobilization. S. meliloti recombinants were selected on LB medium containing $0.3 \mathrm{M}$ sucrose, and either tetracycline or gentamicin. Colonies were screened for neomycin sensitivity.

For treS inactivation, an internal fragment of the ORF was amplified by PCR, cloned into the pGEM-T Easy vector, and introduced in pK18mob. A Gm ${ }^{\mathrm{R}}$ cassette was introduced into the unique XhoI site located in the treS ORF. The resulting recombinant suicide plasmid was transferred into Rm1021 recipient strain by triparental mating. S. meliloti recombinants were selected on LB medium containing neomycin.

For all three genes, insertion was confirmed by PCR. Mutations were periodically transduced to the wild-type background by using $\Phi \mathrm{M} 12$ (Finan et al., 1984).

Transcriptional fusions with uidA. Promoter regions of otsA, tre $Y$ and treS genes were amplified by PCR (primers are described in Table 2; the sequence of the amplified region, and its characteristics, are described in Supplementary Fig. S1, available with the online version of this paper). The amplified fragments were introduced in the uidA promoterless vector pD6796. This plasmid was constructed by insertion of a $2 \mathrm{~kb} P s t \mathrm{I}-K p n \mathrm{I}$ fragment of pTH1522 (Cowie et al., 2006), bearing the promoterless uidA gene, between the NsiI and KpnI sites of pBBRI-MCS2 (a low-copy-number plasmid that is able to replicate in S. meliloti). Recombinant plasmids were transferred to $S$. meliloti wild-type and the rpoE2 mutant by triparental mating.

Enzyme assays. S. meliloti cells were grown in GAS medium, and GAS medium supplemented with $0.5 \mathrm{M} \mathrm{NaCl}(0.5 \mathrm{M} \mathrm{NaCl} \mathrm{GAS})$. Cells were collected by centrifugation $(5000 \mathrm{~g}, 10 \mathrm{~min})$. Protein concentration was determined by the Bradford method, and $\beta$-glucuronidase activity was measured as described previously (Bardonnet \& Blanco, 1992). The results are the means of at least three independent experiments.

Extraction of solutes, and NMR spectroscopy. Major intracellular compounds were extracted and identified by ${ }^{13} \mathrm{C}$ NMR, as described previously (Pichereau et al., 1998).

Assays for compatible solutes. Glutamate and NAGGN were quantified as described previously (Gouffi et al., 1998). For the trehalose assay, cells were grown in GAS medium, collected by centrifugation, and extracted with $80 \%$ ethanol. Extracts were dried under vacuum, resuspended in $0.3 \mathrm{ml} 135 \mathrm{mM}$ citrate buffer, $\mathrm{pH} 5.7$, and $0.1 \mathrm{ml}$ of the extract was blended with $0.4 \mathrm{ml}$ citrate buffer containing $10 \mathrm{mU}$ trehalase from porcine kidney (Sigma). The mixture was incubated at $37^{\circ} \mathrm{C}$ for $2 \mathrm{~h}$, and neutralized by the addition of $0.5 \mathrm{ml} 500 \mathrm{mM}$ Tris buffer, $\mathrm{pH}$ 7.5. A $0.3 \mathrm{ml}$ volume of the trehalase reaction mixture was added to $0.3 \mathrm{ml} 1 \mathrm{mM}$ azinobis(3-ethylbenzothiazoline-6-sulfonic acid) (ABTS) in $50 \mathrm{mM}$ sodium phosphate buffer ( $\mathrm{pH} 7.2$ ) and $0.3 \mathrm{ml}$ of glucose oxidase/ peroxidase reagent (Sigma), and the mixture was incubated at $37{ }^{\circ} \mathrm{C}$ for $20 \mathrm{~min}$. $\mathrm{HCl}$, at a final concentration of $40 \mathrm{mM}$, was added, and the absorbance of oxidized ABTS was measured at $410 \mathrm{~nm}$. The 
Table 1. Bacterial strains and plasmids

\begin{tabular}{|c|c|c|}
\hline Strain/plasmid & Genotype & Origin \\
\hline \multicolumn{3}{|l|}{ E. coli } \\
\hline DH5 $\alpha$ & endA1 hsdR17 supE44 thi-1 recA1 gyrA relA1 $\Delta($ lacZYA-argG)U169 deoR & Hanahan (1983) \\
\hline \multicolumn{3}{|l|}{ S. meliloti } \\
\hline Rm1021 & $\mathrm{SU} 47, \mathrm{Sm}^{\mathrm{R}}$ & Meade et al. (1982) \\
\hline R641 & $\mathrm{Rm} 1021, r p o E 2:: \mathrm{Gm}^{\mathrm{R}}$ & Flechard et al. (2009) \\
\hline R826 & $\operatorname{Rm} 1021$, ots $A:: \mathrm{Tc}^{\mathrm{R}}$ & This study \\
\hline R779 & $\operatorname{Rm} 1021$, treY:: $\mathrm{Gm}^{\mathrm{R}}$ & This study \\
\hline R950 & Rm 1021, treS:: $\mathrm{Gm}^{\mathrm{R}}$ & This study \\
\hline \multicolumn{3}{|l|}{ Plasmids } \\
\hline pGEM-T Easy & pUC derivative cloning vector, $\mathrm{Ap}^{\mathrm{R}}$ & Promega \\
\hline pK18mob & Mobilizable pUC derivative & Schafer et al. (1994) \\
\hline pHP45 $\Omega$ Tet & ori ColEI $\mathrm{Ap}^{\mathrm{R}} \Omega \mathrm{Tc}^{\mathrm{R}}$ cassette & Fellay et al. (1987) \\
\hline p34SGm & ori ColEI Ap ${ }^{R} \mathrm{Gm}^{\mathrm{R}}$ cassette & Dennis \& Zylstra (1998) \\
\hline $\mathrm{pUIDK}_{3}$ & pUC18 derivative bearing a 'uidA-Neo ${ }^{\mathrm{R}}$ cassette & Bardonnet \& Blanco (1992) \\
\hline pD6796 & pBBRI-MCS2, uidA promoterless & This study \\
\hline pD3532 & pK18mobsacB rpoE2: : lacZ-Gm ${ }^{\mathrm{R}}$ & This study \\
\hline pD9186 & pK18mob tres & This study \\
\hline pD7548 & pK18mobsacB treY:: $\mathrm{Gm}^{\mathrm{R}}$ & This study \\
\hline pD7539 & pK18mobsacB ots $A:: \mathrm{Tc}^{\mathrm{R}}$ & This study \\
\hline pD7474 & pD6796 treS-uidA & This study \\
\hline pD7463 & pD6796 treY-uidA & This study \\
\hline pD6951 & pD6796 otsA-uidA & This study \\
\hline
\end{tabular}

glucose concentration was determined according to a calibration performed with a glucose standard solution (Sigma), which was treated as described above. The amount of glucose present in cellular extracts was determined using the protocol described above, with the omission of the trehalase action. The results are the means of three independent experiments.
Complementation of rpoE2 mutant with otsA of S. meliloti. Using the primers otsAD and otsAR (Table 2), the otsA gene was amplified as a $1.4 \mathrm{~kb}$ DNA fragment containing the otsA ORF with its ribosome-binding site, but without its promoter. The amplicon was cloned in pGEM-T Easy. The insert was cleaved as an EcoRI fragment, and cloned into pBBRI-MCS2 into the unique EcoRI restriction site.

Table 2. Oligonucleotide primers used in this study

\begin{tabular}{|c|c|c|}
\hline Primer name & Sequence $\left(5^{\prime} \rightarrow 3^{\prime}\right)$ & Gene description \\
\hline MutotsAG & TGGTCTTCGACGGCTCGGA & ots $A$ \\
\hline MutotsAD & CATGGCTTCGTATTCCGGCAC & \\
\hline MuttreYG & GACGTGCTTGAAGAGGCCG & treY \\
\hline MuttreYD & GGTGTCGTGCGTGGAGGTAG & \\
\hline MuttreSintG & GATGAAAGAGGCGCCGTGG & tres \\
\hline MuttreSD2 & GGCTGCAAAGGTTTCСTCTC & \\
\hline grOTSA5 & CGTCCACGCCCCCCGAATC & Promoter region of otsA \\
\hline grOTSA3 & AGGGACGGGCACACGATTGG & \\
\hline b20574G & GAATTCTCGCTTTAGCTCCCCGTG & Promoter region of $\operatorname{tre} Y$ \\
\hline b20574D & AAGCTTCATGGCGGTCTTGCAC & \\
\hline opb20099G & GAATTCTCCTATCCCGTACGTGGC & Promoter region of treS \\
\hline opb20099D & AAGCTTCATATTTGCСССТССТСС & \\
\hline otsAD & CTTGAATGAAAGGAATTCGGC & Promoterless otsA ORF \\
\hline otsAR & GCATGATGCTGGCAGGCAG & \\
\hline
\end{tabular}


The orientation allowing ots $A$ transcription from the lac promoter in the plasmid was selected, and the plasmid was named pE219. This plasmid was transferred into $S$. meliloti by triparental mating, and clones containing the plasmid were selected as $\mathrm{Sm}^{\mathrm{R}}, \mathrm{Nm}^{\mathrm{R}}$ colonies.

\section{RESULTS}

\section{Osmotic behaviour of the rpoE2 mutant}

Wild-type and rpoE2 strains were inoculated into GAS medium and $0.5 \mathrm{M} \mathrm{NaCl}$ GAS medium (Fig. 1). In nonsalted GAS medium, rpoE2 growth was identical to that of the parental strain. In contrast, in $0.5 \mathrm{M} \mathrm{NaCl}$ GAS medium, rpoE2 cells showed a reduced growth rate and growth yield compared with the wild-type strain. This defect was linked to osmolarity, since when $0.5 \mathrm{M} \mathrm{NaCl}$ was substituted with $1 \mathrm{M}$ galactose (which develops the same osmotic strength), the same difference in growth rate and yield was observed for rpoE2 and the wild-type (data not shown).

\section{Influence of osmoprotectants on the growth of the rpoE2 mutant in medium of high osmotic strength}

In $0.5 \mathrm{M} \mathrm{NaCl}$ GAS medium, the growth of Rm1021 was improved when an osmoprotectant (sucrose, ectoine or $\mathrm{HB}$ ) was added. Addition of sucrose or ectoine resulted in a slight improvement in the growth of the rpoE2 strain in $0.5 \mathrm{M} \mathrm{NaCl}$ GAS medium, but the growth rate and growth

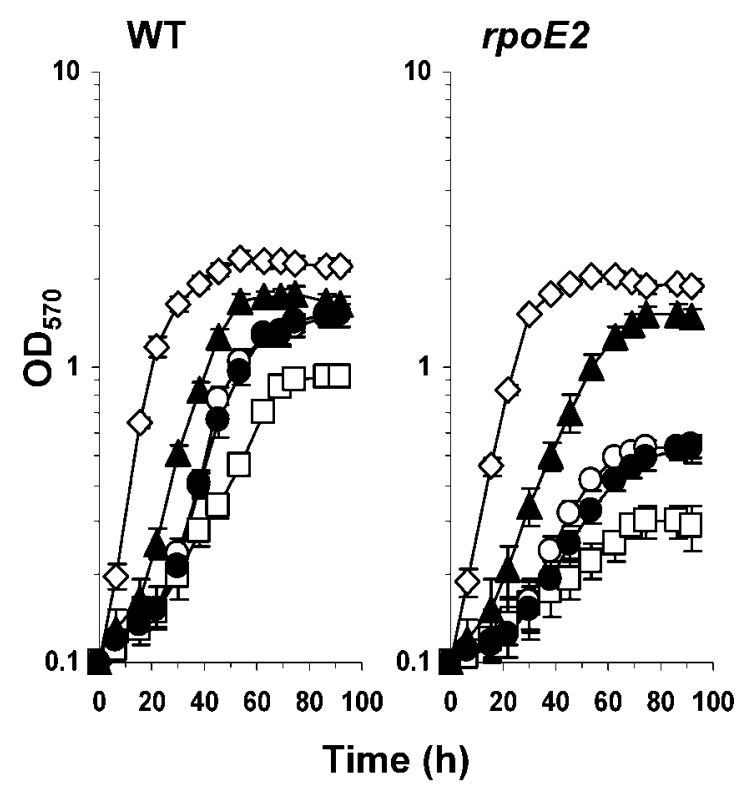

Fig. 1. Influence of osmoprotectants on growth of Rm1021 (wildtype, WT) and the rpoE2 mutant. The strains were inoculated into GAS medium $(\diamond), 0.5 \mathrm{M} \mathrm{NaCl}$ GAS medium $(\square)$, and $0.5 \mathrm{M} \mathrm{NaCl}$ GAS medium supplemented with an osmoprotectant $(1 \mathrm{mM})$ : sucrose $(\bigcirc)$, ectoine $(\mathbf{O})$ or homobetaine $(\boldsymbol{A})$. Error bars, SD. yield were lower than those obtained with the parental strain (Fig. 1). In contrast, addition of HB improved the growth of rpoE2 to levels that were similar to those of the wild-type (Fig. 1). Thus, HB was a powerful osmoprotectant for $r p o E 2$, while the efficiency of the non-accumulated osmoprotectants ectoine and sucrose was reduced in rpoE2.

\section{Growth phase and osmotic regulation of rpoE2}

The regulation of rpoE2 was analysed in the R635 strain carrying a wild-type copy of rpoE2 and a rpoE2-uidA fusion in the chromosome (Flechard et al., 2009). Expression of the fusion was analysed throughout growth in GAS medium. $\beta$-Glucuronidase activity was low and constant during the exponential growth phase [the amount of substrate hydrolysed was $5 \pm 1 \mu \mathrm{mol} \mathrm{min} \mathrm{mi}^{-1}$ (mg protein $)^{-1}$, but it increased as soon as cells entered the stationary growth phase, when substrate hydrolysis reached a level of $30 \pm 2 \mu \mathrm{mol} \mathrm{min}{ }^{-1}$ (mg protein) ${ }^{-1}$ (Fig. 2); these results were in accordance with previous observations (Flechard et al., 2009; Sauviac et al., 2007). When cells were inoculated into $0.5 \mathrm{M} \mathrm{NaCl} \mathrm{GAS} \mathrm{medium,} \beta$-glucuronidase activity increased immediately from $5 \pm 1 \mu \mathrm{mol} \mathrm{min}^{-1}$ (mg protein $)^{-1}$ to $10.0 \pm 1.5 \mu \mathrm{mol} \mathrm{min}^{-1}(\mathrm{mg} \text { protein })^{-1}$, and it remained stable during exponential growth. The activity increased again at the end of exponential phase to reach $28.7 \pm 2.2 \mu \mathrm{mol} \mathrm{min}{ }^{-1}(\mathrm{mg} \text { protein })^{-1}$. Addition of $1 \mathrm{mM}$ sucrose to $0.5 \mathrm{M} \mathrm{NaCl}$ GAS medium resulted in improved growth, but it did not modify the $\beta$-glucuronidase activity pattern (Fig. 2). In contrast, addition of $1 \mathrm{mM} \mathrm{HB}$ to $0.5 \mathrm{M} \mathrm{NaCl}$ GAS medium abolished the osmotic induction of rpoE2 during exponential growth, and drastically reduced its expression during the stationary growth phase (Fig. 2). These results suggest that rpoE2 is an osmoresponsive gene.

\section{Osmolyte content of rpoE2 mutant}

In S. meliloti, osmoprotection by $\mathrm{HB}$ results from its accumulation (Barra et al., 2006). In contrast, in the absence of osmoprotectants, or in the presence of nonaccumulated osmoprotectants, osmoprotection is achieved by the synthesis and accumulation of glutamate, NAGGN and trehalose (Gouffi et al., 1999; Jebbar et al., 2005). The growth of the rpoE2 mutant is affected in hyperosmotic medium deprived of osmoprotectants or containing nonaccumulated osmoprotectants, suggesting that synthesis of glutamate, NAGGN or trehalose is affected.

Wild-type and rpoE2 strains were grown in $0.5 \mathrm{M} \mathrm{NaCl}$ GAS medium, and the osmolyte content was analysed by ${ }^{13} \mathrm{C}$ NMR (Fig. 3). Cells were collected during exponential growth $\left(\mathrm{OD}_{570} 0.4\right.$ and 0.2 for parental and rpoE2 strains, respectively) and at the end of exponential growth $\left(\mathrm{OD}_{570}\right.$ 0.9 and 0.4 for wild-type and rpoE2 strains, respectively). Glutamate and NAGGN were observed in ethanolic extracts of both strains in the two conditions analysed (Fig. 3). The amount of glutamate and NAGGN was 


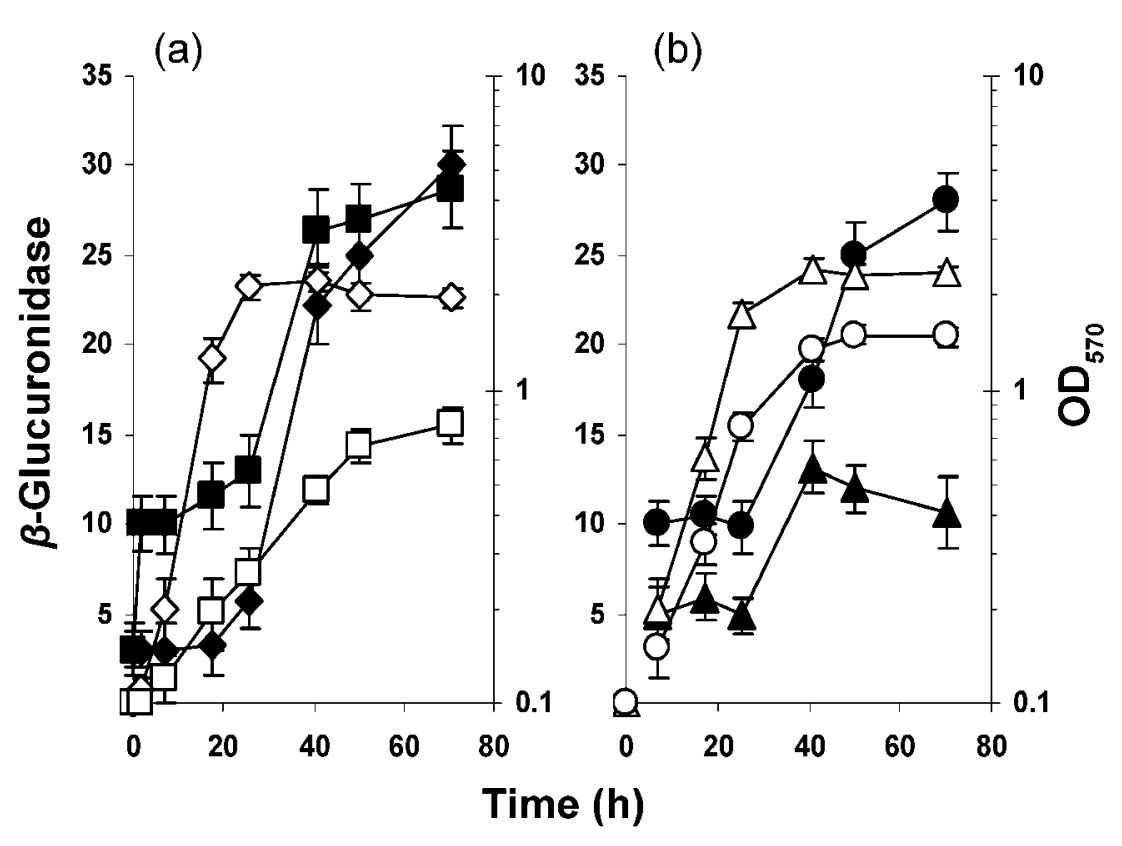

Fig. 2. Influence of medium osmolarity and osmoprotectants on rpoE2 expression. Growth of R635 (rpoE2 $^{+}$rpoE2 : : uidA; open symbols) and $\beta$-glucuronidase activity [measured as the amount of substrate hydrolysed, $\mu \mathrm{mol} \min ^{-1}$ (mg protein $)^{-1}$; closed symbols] were analysed in (a) GAS medium (diamonds) and $0.5 \mathrm{M} \mathrm{NaCl}$ GAS medium (squares), and (b) $0.5 \mathrm{M} \mathrm{NaCl}$ GAS medium containing $1 \mathrm{mM}$ $\mathrm{HB}$ (triangles) or $1 \mathrm{mM}$ sucrose (circles). The results are the means $( \pm S D)$ of three independent experiments.

identical in both strains $[620 \pm 35$ and $160 \pm 22 \mathrm{nmol}(\mathrm{mg}$ protein $)^{-1}$ for glutamate and NAGGN, respectively, in early exponential growth, and $440 \pm 28$ and $230 \pm 32 \mathrm{nmol}$ $(\mathrm{mg} \text { protein })^{-1}$ for glutamate and NAGGN, respectively, in late exponential growth]. In Rm1021, trehalose was observed during exponential growth as a minor solute, and its abundance increased at the end of exponential growth (Fig. 3). In contrast, trehalose was not detected in the extracts of rpoE2 strain either during or at the end of exponential growth (Fig. 3).
The trehalose content was quantified in cells grown in $0.5 \mathrm{M} \mathrm{NaCl}$ GAS medium. In the wild-type strain, it increased continuously throughout growth to reach its maximal level after growth for $48 \mathrm{~h}[140 \pm 11 \mathrm{nmol}(\mathrm{mg}$ protein $)^{-1}$; this value is similar to the level found in strain $102 \mathrm{~F} 34$ in the same experimental conditions (Gouffi et al., 1999; Jebbar et al., 2005; Talibart et al., 1994). Trehalose was not detected in the rpoE2 mutant in the same experimental conditions. In non-salted GAS medium, trehalose was not detected during exponential growth of

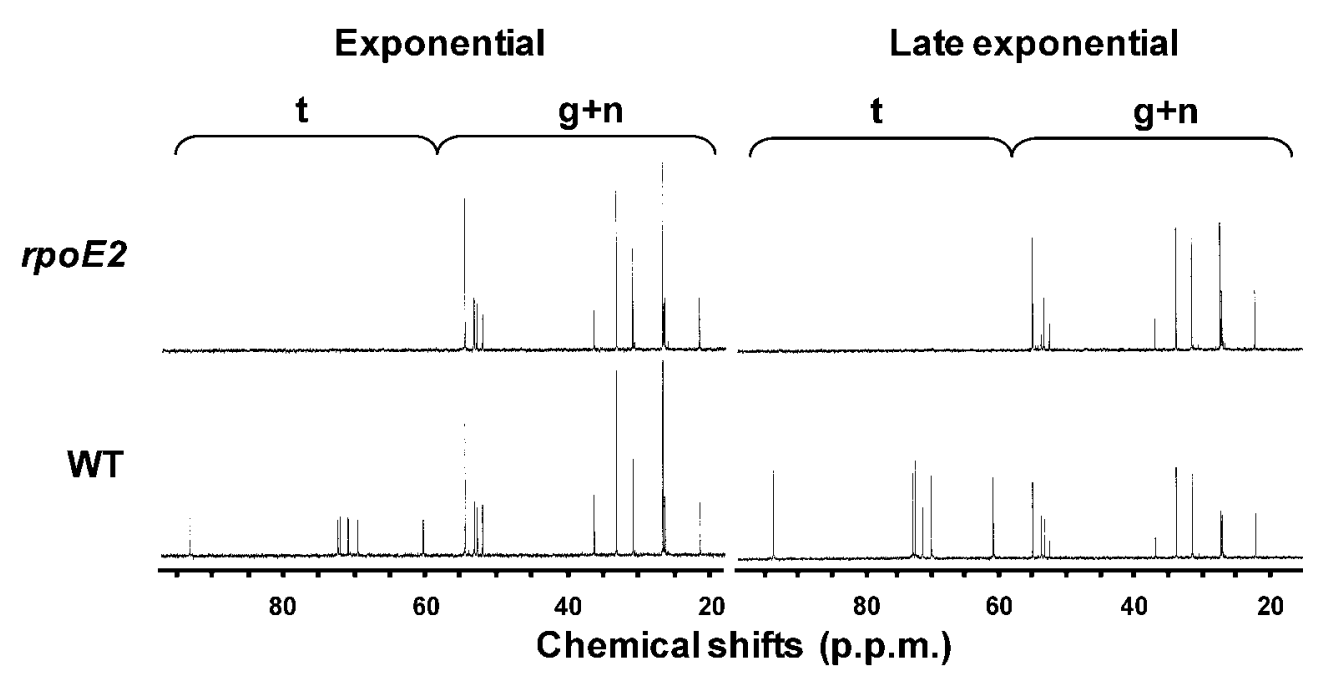

Fig. 3. Identification of compatible solutes accumulated in medium of high osmotic strength. Wild-type (WT) and rpoE2 strains were grown in $0.5 \mathrm{M} \mathrm{NaCl}$ GAS medium. Cells were collected during exponential growth $\left(\mathrm{OD}_{570} 0.4\right.$ and 0.2 for WT and rpoE2, respectively) and at the end of exponential growth ( $\mathrm{OD}_{570} 0.9$ and 0.4 for WT and rpoE2, respectively), and ethanolic extracts of the cells were analysed by ${ }^{13} \mathrm{C}$ NMR. Peaks corresponding to trehalose $(\mathrm{t})$, and glutamate and $N A G G N(g+n)$, are indicated. 
Rm1021 and the rpoE2 mutant, but it reached a level of $0.23 \pm 0.03 \mathrm{nmol}$ (mg protein $)^{-1}$ in the stationary growth phase for Rm1021, while it was not detected in the rpoE2 strain. Thus, rpoE2 affects trehalose synthesis during osmotic adaptation, and also during the stationary growth phase.

\section{Trehalose biosynthesis genes are under the control of rpoE2}

BLAST analysis revealed that SMa0233 and SMb20574 had 78 and $48 \%$ identity to OtsA and TreY, respectively, of Rhizobium leguminosarum (McIntyre et al., 2007). SMb20099 has 39\% identity with TreS from the alphaproteobacterium Rhodobacter sphaeroides sp. denitrificans. SMa0233, SMb20574 and SMb20099 are therefore referred to as OtsA, TreY and TreS, respectively, hereafter. These three ORFs are induced by osmotic stress, as described in the transcriptomic study by Domínguez-Ferreras et al. (2006). A sequence close to the consensus of the rpoE2 promoter (ggAAC-16-17 nt-gcgTTt) proposed by Sauviac et al. (2007) is located upstream of the operon they proposed, suggesting a putative rpoE2-dependent transcript (Supplementary Fig. S1).

To analyse the regulation and rpoE2 dependence of otsA, treS and treY of S. meliloti, transcriptional fusions with uidA were constructed on a low-copy-number plasmid, and introduced into $\mathrm{Rm} 1021$ and rpoE2 strains. $\beta$-Glucuronidase activity was assayed during growth in GAS medium (Fig. 4). $\beta$-Glucuronidase activity was not observed when cells containing the empty vector were grown in GAS medium or $0.5 \mathrm{M} \mathrm{NaCl}$ GAS medium. Expression of treY-uidA and treS-uidA fusions was strongly induced in the wild-type strain during the stationary growth phase, while activity of the otsA-uidA fusion was very low throughout growth. Stationarygrowth-phase induction of treY and treS was abolished in the rpoE2 mutant (Fig. 4). These results suggest that rpoE2 is required for treY and treS induction during the stationary growth phase. When wild-type cells containing
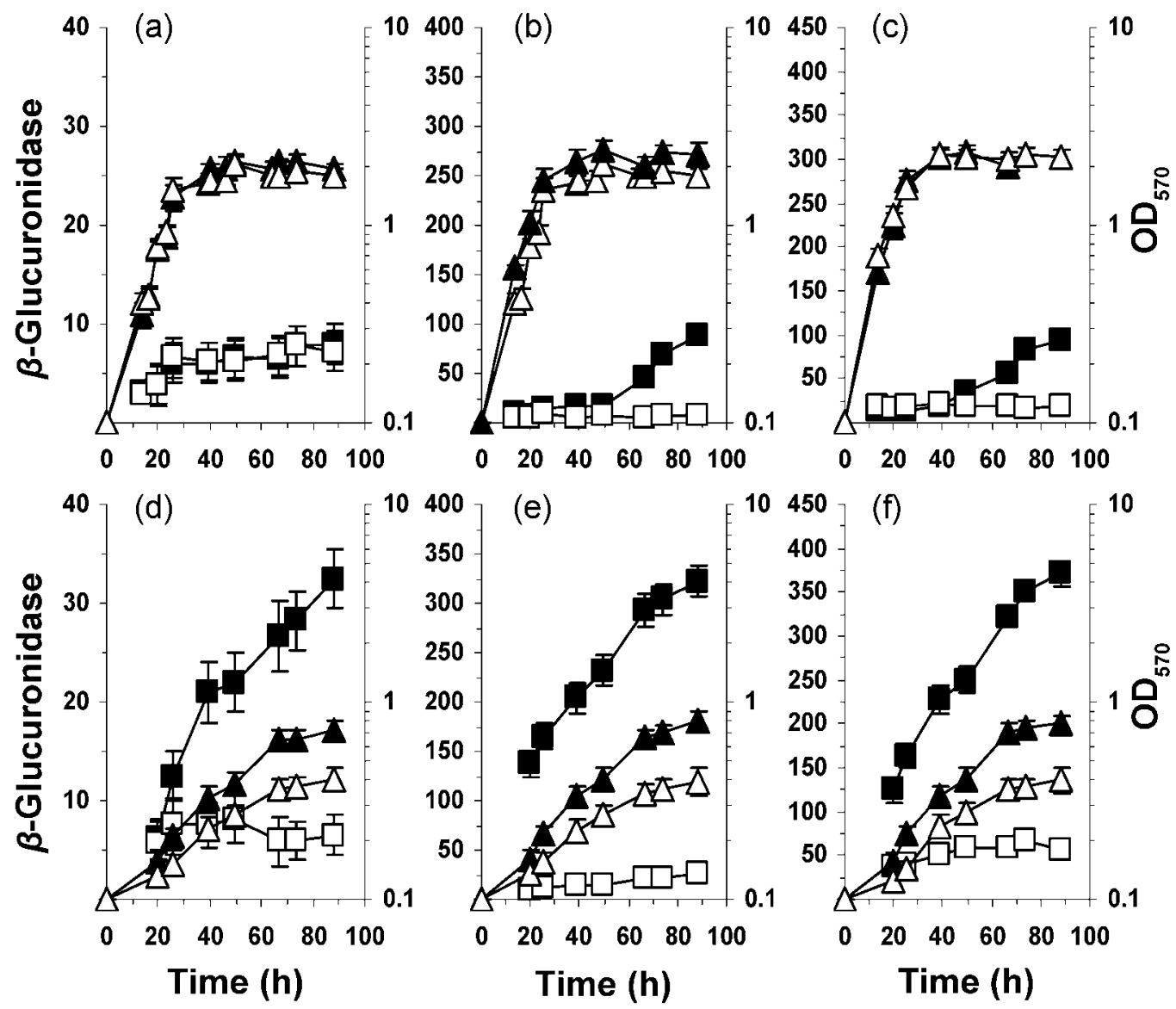

Fig. 4. Influence of $r p o E 2$ on the growth phase and osmotic dependence of ots $A$, treS and tre $Y$ expression. Rm1021 (closed symbols) and rpoE2 (open symbols) containing pD6951 (ots $A$-uidA) (a, d), pD7463 (tre $Y$-uidA) (b, e) or pD7474 (treS-uidA) $(\mathrm{c}, \mathrm{f})$ were grown in GAS medium $(\mathrm{a}, \mathrm{b}, \mathrm{c})$ or $0.5 \mathrm{M} \mathrm{NaCl} \mathrm{GAS}$ medium (d, e, f). Growth, represented by $\mathrm{OD}_{570}$ (triangles), and $\beta$-glucuronidase specific activity [measured as the amount of substrate hydrolysed, $\mu \mathrm{mol} \mathrm{min}^{-1}$ (mg protein) ${ }^{-1}$ ] (squares) were determined at time intervals. The results are the means $( \pm S D)$ of three independent experiments. 
these plasmids were grown in $0.5 \mathrm{M} \mathrm{NaCl}$ GAS medium, expression of otsA, treY and treS fusions increased continuously during the exponential growth phase to reach maximal activity at the end of the growth phase (6-, 20and 40 -fold increases in induction, respectively). This induction by $\mathrm{NaCl}$ was abolished in the rpoE2 mutant (Fig. 4), suggesting that rpoE2 is necessary for osmotic induction of otsA, treY and treS genes.

The osmotic induction of otsA, treY and treS is in agreement with the results obtained in transcriptomic work by Domínguez-Ferreras et al. (2006). Our results show that the expression of treS and treY was under the control of rpoE2 during the stationary growth phase in non-stressing medium. Moreover, the osmotic induction of otsA, treY and treS during the exponential growth phase was rpoE2 dependent.

\section{Trehalose content and growth behaviour of S. meliloti otsA, treY and treS mutants}

In order to confirm the role of otsA, treS and $\operatorname{tre} Y$ in trehalose synthesis during growth in GAS medium and $0.5 \mathrm{M} \mathrm{NaCl}$ GAS medium, growth parameters and trehalose content were analysed in the wild-type, and in rpoE2, otsA, treY and treS mutants. Mutations in rpoE2, otsA, treY or treS did not affect growth in GAS medium. Trehalose was not detected in any of the mutants or the wild-type during the exponential growth phase. It accumulated in Rm1021 during the stationary growth phase $\left.[0.23 \pm 0.03 \mathrm{nmol} \text { (mg protein })^{-1}\right]$; this level was not affected by otsA and treS mutations. In contrast, trehalose was not detected in rpoE2 and treY strains collected in the stationary growth phase in GAS medium, suggesting that stationary-growth-phase accumulation of trehalose in nonstressing conditions results from TreY activity.

Growth of rpoE2 and otsA strains in $0.5 \mathrm{M} \mathrm{NaCl}$ GAS medium was reduced in comparison with the wild-type strain (Fig. 5). In contrast, the treY and treS mutants grew to levels that were almost identical to the parental strain (Fig. 5). The intracellular content of trehalose increased in the wild-type strain, and treS and treY strains, throughout growth, to reach a maximal level in the middle of the exponential growth phase that was almost identical for each of the three strains(Fig. 5). The trehalose content was negligible in rpoE2 and otsA mutants during all phases of growth (Fig. 5). The trehalose content and the ability to grow in hyperosmotic media were correlated, suggesting that $S$. meliloti needs to accumulate trehalose for optimal growth in medium containing $0.5 \mathrm{M} \mathrm{NaCl}$.

\section{The rpoE2 osmotic phenotype is complemented by the $S$. meliloti otsA gene}

Osmotic induction of otsA was RpoE2 dependent; therefore, to analyse whether the rpoE2 defect results from the absence of transcription of the otsA gene only, the rpoE2 mutant was complemented by pE219 expressing a (a)

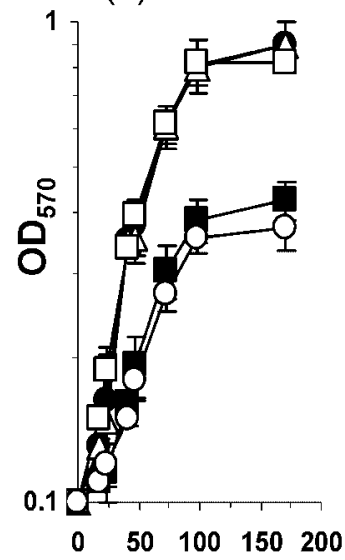

(b)

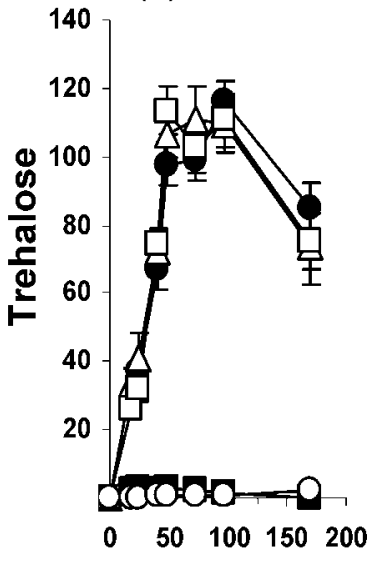

Time (h)
Fig. 5. Growth and trehalose content of otsA, tre $Y$ and treS mutants in medium of high osmotic strength. Wild-type Rm1021 $(\bullet), \operatorname{rpoE2}(\bigcirc)$, ots $A(\boldsymbol{\square})$, tre $Y(\triangle)$ and treS $(\square)$ were inoculated into $0.5 \mathrm{M} \mathrm{NaCl}$ GAS medium. (a) Growth $\left(\mathrm{OD}_{570}\right)$, and (b) trehalose content $\left[\mathrm{nmol}(\mathrm{mg} \text { protein })^{-1}\right]$ were measured periodically. The results are the means $( \pm S D)$ of three independent experiments.

promoterless otsA gene from the lac promoter of pBBRIMCS2. Wild-type and rpoE2 strains bearing pBBRI-MCS2 behave similarly to the corresponding bacteria without the plasmid. Growth patterns of the wild-type strain containing pE219 did not show a significant difference compared with the strain containing the empty vector (Fig. 6). In contrast, introduction of pE219 into the rpoE2 strain abolished the growth defect in $0.5 \mathrm{M} \mathrm{NaCl}$ GAS medium (Fig. 6). Thus, the expression of otsA from the lac promoter suppressed the osmotic phenotype of rpoE2 mutant, demonstrating that this phenotype was caused by a lack of ots $A$ transcription.

\section{DISCUSSION}

The ability of $S$. meliloti to adapt to hyperosmotic media is linked to the synthesis and accumulation of organic osmolytes. Glutamate and NAGGN are the major solutes present during exponential growth; they have been described as the main factors affecting turgor (Gouffi et al., 1999; Talibart et al., 1997), and their levels are not affected by the rpoE2 mutation. The glutamate level increases, and reaches a maximum level a few minutes after exposure to high osmolarity; it then decreases as the levels of NAGGN and trehalose increase (Gouffi et al., 1998). NAGGN and trehalose reach their maximal level in the middle of exponential growth, and NAGGN is fivefold more abundant than trehalose. The level of NAGGN then decreases, while that of trehalose remains constant (Gouffi et al., 1998). While trehalose appears as a minor solute during growth (Gouffi et al., 1998; Talibart et al., 1994, 


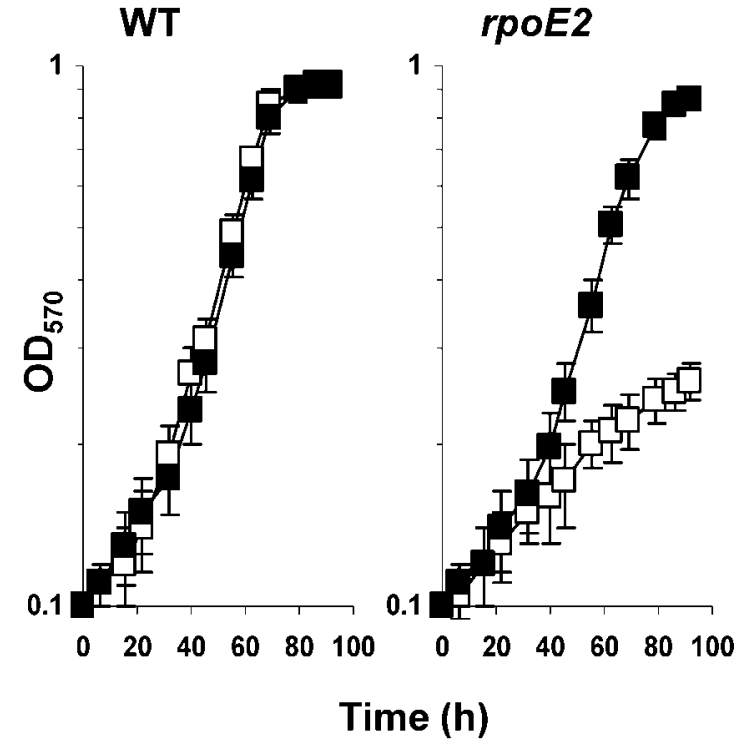

Fig. 6. Complementation of the rpoE2 mutation with the $S$. meliloti ots $A$ gene. Wild-type (WT) and the rpoE2 mutant containing pBBR1-MCS2 empty vector (open symbols) or pE219 (closed symbols) were grown in $0.5 \mathrm{M} \mathrm{NaCl}$ GAS medium. The results are the means $( \pm S D)$ of three independent experiments.

1997), we show in this study that trehalose synthesis is crucial for growth in hyperosmotic media.

Three pathways of trehalose synthesis have been described in S. meliloti (Streeter \& Bhagwat, 1999; Streeter \& Gomez, 2006). We did not characterize all the genes corresponding to these pathways, but we analysed the expression of a specific gene in each pathway (treS, treY and otsA). These three genes are regulated by rpoE2. Inactivation of treS did not affect trehalose synthesis in GAS medium; as described in Propionibacterium freudenreichii, TreS might be involved in trehalose degradation (Cardoso et al., 2007). The treY mutation suppressed trehalose synthesis in the lowosmolarity medium during the stationary growth phase. Only the otsA mutation abolished osmoregulated trehalose synthesis, and affected growth in hyperosmotic medium. Osmoregulated trehalose synthesis is mediated by TreYZ in Corynebacterium glutamicum (Wolf et al., 2003). Nevertheless, in most bacteria possessing the three trehalose pathways, OtsAB is the main pathway for osmoregulated trehalose synthesis, as observed in Mycobacterium tuberculosis (Murphy et al., 2005), Rhodobacter sphaeroides (Makihara et al., 2005) and P. freudenreichii (Cardoso et al., 2007).

Osmotic stress is a component of other phenomena, such as desiccation. The rpoE2 mutation drastically reduces survival during desiccation (Humann et al., 2009). Trehalose accumulation is involved in desiccation resistance of Rhizobium leguminosarum; mutants that do not accumulate trehalose are sensitive to drying (McIntyre et al., 2007). Desiccation tolerance is improved when cells are collected during the stationary growth phase (Vriezen et al., 2007). This corresponds to maximal induction of rpoE2 and trehalose accumulation by S. meliloti. Our results showed that RpoE2 is required for trehalose synthesis, suggesting that the rpoE2 defect in desiccation tolerance is due to the control of trehalose biosynthesis by rpoE2.

In this study, we have shown that trehalose is essential for optimal growth in hyperosmotic media, despite its low level during the initial stages of growth compared with the two other organic osmolytes produced by $S$. meliloti. This suggests that trehalose participation in osmoadaptation is not only limited to turgor recovery but also involves protective properties of trehalose against macromolecule denaturation (Yancey, 2005). This is consistent with accumulation of trehalose during the stationary growth phase when turgor is not essential. The important role of trehalose during desiccation is also consistent with its protective role on macromolecules (Humann et al., 2009). This cytoprotective role of trehalose and its dependence on RpoE2 might explain, in part, the importance of RpoE2 as a general stress factor (Sauviac et al., 2007), even though specific rpoE2-dependent genes have not been identified for each stress.

The regulation of trehalose synthesis has been studied at the molecular level in E. coli and Salmonella typhimurium only. In these two related bacteria, trehalose is exclusively produced by the OtsBA pathway. The otsBA operon is regulated by RpoS, which has been identified as a general stress factor (Hengge-Aronis, 2002). RpoS allows the transcription of the otsBA operon in stationary phase and also in osmotically stressed cells during exponential growth (Kaasen et al., 1992). The trehalose level is very low in E. coli during the stationary phase in low-osmotic media; trehalose synthase is activated by potassium glutamate, allowing a high trehalose level during osmotic stress (Giaever et al., 1988). The rpoS gene is not present in the S. meliloti genome (Galibert et al., 2001), but trehalose synthesis has similar traits in S. meliloti and E. coli. It is produced at a low level during stationary phase in nonstressing media, and its synthesis is activated by osmotic stress. In both S. meliloti and E. coli, and in all growth conditions, trehalose synthesis is controlled by an alternative sigma factor (RpoS for enterobacteria and RpoE2 for S. meliloti). These sigma factors have a more general role in stress regulation, since they control genes involved in adaptation to other stresses (Flechard et al., 2009; HenggeAronis, 2002; Sauviac et al., 2007). In this respect, RpoE2 has a role that is very similar to that of E. coli RpoS. In this study, we observed that $S$. meliloti otsA is not induced in stationary phase in low-osmotic media, but during osmotic stress only; in contrast, $\operatorname{tre} Y$ and treS are induced in both conditions. This suggests that transcription of ots $A$ is not only RpoE2 dependent but that it is also affected by another regulatory process. In E. coli, the transcription of some osmoregulated genes, such as $\operatorname{proP}$ and $o t s A$, requires not only RpoS, but also transcriptional and post-transcriptional regulators (Kunte et al., 1999; McLeod et al., 2000). In S. meliloti, RpoE2 participates in osmoregulation; 
however, much work is necessary to identify the molecular mechanisms of its action.

The osmotic induction of treS and treY suggests that these two genes play a role in osmoadaptation that was not revealed under our experimental conditions. A recent study (Domínguez-Ferreras et al., 2009) performed in a different growth medium showed OtsA to be the main factor for trehalose synthesis under salt stress conditions, but it also showed participation of TreS and TreY in trehalose synthesis under stress conditions. The influence of medium composition on trehalose synthesis has been described in S. meliloti (Streeter, 1985) and other micro-organisms (Seto et al., 2004). The three pathways use different precursors for trehalose synthesis; the availability of precursors depends on medium composition and affects the pathway used for trehalose biosynthesis (Carpinelli et al., 2006). TreS uses maltose as substrate; the medium used in our study did not contain maltose, hence TreS was not relevant. A similar situation has been described in C. glutamicum, where TreS-mediated trehalose synthesis occurred only when maltose was used as the carbon source (Wolf et al., 2003). The TreY pathway is dependent on glycogen availability (Carpinelli et al., 2006). Significant differences in glycogen biosynthesis have been shown as a function of the metabolic state of the cells and the carbon source (Encarnación et al., 2002; Tavernier et al., 1998). Precursors not only affect metabolic flux (Carpinelli et al., 2006) but also are input signals in regulatory circuits (Pinedo et al., 2008). Glycogen metabolism is connected to other major cellular processes by a complex regulatory network (Eydallin et al., 2007). Many global regulators that sense medium status are also involved in $g l g$ gene regulation in E. coli (Montero et al., 2009). Sauviac et al. (2007) showed that glycogen biosynthesis genes in S. meliloti are induced by starvation, and are RpoE2dependent. The regulatory proteins mediating signal transduction to rpoE2 promoters remain to be identified.

\section{ACKNOWLEDGEMENTS}

We thank S. Georgeault, C. Monnier, M. Uguet and M. C. Savary for technical assistance, and A. Holmes for English improvement. This work was supported by the CNRS and the Ministère de la Recherche.

\section{REFERENCES}

Bardonnet, N. \& Blanco, C. (1992). 'uidA-antibiotic-resistance cassettes for insertion mutagenesis, gene fusions and genetic constructions. FEMS Microbiol Lett 72, 243-248.

Barra, L., Fontenelle, C., Ermel, G., Trautwetter, A., Walker, G. C. \& Blanco, C. (2006). Interrelations between glycine betaine catabolism and methionine biosynthesis in Sinorhizobium meliloti strain 102F34. J Bacteriol 188, 7195-7204.

Becker, A., Schmidt, M., Jager, W. \& Puhler, A. (1995). New gentamicin-resistance and lacZ promoter-probe cassettes suitable for insertion mutagenesis and generation of transcriptional fusions. Gene $162,37-39$.
Bourot, S., Sire, O., Trautwetter, A., Touzé, T., Wu, L. W., Blanco, C. \& Bernard, T. (2000). Glycine betaine-assisted protein folding in a $l y s A$ mutant of Escherichia coli. J Biol Chem 275, 1050-1056.

Cardoso, F. S., Castro, R. F., Borges, N. \& Santos, H. (2007). Biochemical and genetic characterization of the pathways for trehalose metabolism in Propionibacterium freudenreichii, and their role in stress response. Microbiology 153, 270-280.

Carpinelli, J., Kramer, R. \& Agosin, E. (2006). Metabolic engineering of Corynebacterium glutamicum for trehalose overproduction: role of the TreYZ trehalose biosynthetic pathway. Appl Environ Microbiol 72, 1949-1955.

Cowie, A., Cheng, J., Sibley, C. D., Fong, Y., Zaheer, R., Patten, C. L., Morton, R. M., Golding, G. B. \& Finan, T. M. (2006). An integrated approach to functional genomics: construction of a novel reporter gene fusion library for Sinorhizobium meliloti. Appl Environ Microbiol 72, 7156-7167.

Crowe, J. H. (2007). Trehalose as a 'chemical chaperone': fact and fantasy. Adv Exp Med Biol 594, 143-158.

da Costa, M. S., Santos, H. \& Galinski, E. A. (1998). An overview of the role and diversity of compatible solutes in Bacteria and Archaea. Adv Biochem Eng Biotechnol 61, 117-153.

Dennis, J. J. \& Zylstra, G. J. (1998). Plasposons: modular self-cloning minitransposon derivatives for rapid genetic analysis of Gramnegative bacterial genomes. Appl Environ Microbiol 64, 2710-2715.

De Smet, K. A., Weston, A., Brown, I. N., Young, D. B. \& Robertson, B. D. (2000). Three pathways for trehalose biosynthesis in mycobacteria. Microbiology 146, 199-208.

Diamant, S., Eliahu, N., Rosenthal, D. \& Goloubinoff, P. (2001). Chemical chaperones regulate molecular chaperones in vitro and in cells under combined salt and heat stresses. J Biol Chem 276, 3958639591.

Domínguez-Ferreras, A., Pérez-Arnedo, R., Becker, A., Olivares, J., Soto, M. J. \& Sanjuán, J. (2006). Transcriptome profiling reveals the importance of plasmid pSymB for osmoadaptation of Sinorhizobium meliloti. J Bacteriol 188, 7617-7625.

Domínguez-Ferreras, A., Soto, M. J., Pérez-Arnedo, R., Olivares, J. \& Sanjuán, J. (2009). Importance of trehalose biosynthesis for Sinorhizobium meliloti osmotolerance and nodulation of alfalfa roots. J Bacteriol 191, 7490-7499.

Encarnación, S., del Carmen Vargas, M., Dunn, M. F., Dávalos, A., Mendoza, G., Mora, Y. \& Mora, J. (2002). AniA regulates reserve polymer accumulation and global protein expression in Rhizobium etli. J Bacteriol 184, 2287-2295.

Eydallin, G., Viale, A. M., Morán-Zorzano, M. T., Muñoz, F. J., Montero, M., Baroja-Fernández, E. \& Pozueta-Romero, J. (2007). Genome-wide screening of genes affecting glycogen metabolism in Escherichia coli K-12. FEBS Lett 581, 2947-2953.

Fang, F. C., Chen, C. Y., Guiney, D. G. \& Xu, Y. (1996). Identification of $\sigma \mathrm{S}$-regulated genes in Salmonella typhimurium: complementary regulatory interactions between $\sigma \mathrm{S}$ and cyclic AMP receptor protein. $J$ Bacteriol 178, 5112-5120.

Fellay, R., Frey, J. \& Krisch, H. (1987). Interposon mutagenesis of soil and water bacteria: a family of DNA fragments designed for in vitro insertional mutagenesis of Gram-negative bacteria. Gene 52, 147-154.

Finan, T. M., Hartweig, E., LeMieux, K., Bergman, K., Walker, G. C. \& Signer, E. R. (1984). General transduction in Rhizobium meliloti. J Bacteriol 159, 120-124.

Finan, T. M., Hirsch, A. M., Leigh, J. A., Johansen, E., Kuldau, G. A., Deegan, S., Walker, G. C. \& Signer, E. R. (1985). Symbiotic mutants of Rhizobium meliloti that uncouple plant from bacterial differentiation. Cell 40, 869-877. 
Flechard, M., Fontenelle, C., Trautwetter, A., Ermel, G. \& Blanco, C. (2009). Sinorhizobium meliloti rpoE2 is necessary for $\mathrm{H}_{2} \mathrm{O}_{2}$ stress resistance during the stationary growth phase. FEMS Microbiol Lett 290, 25-31.

Galibert, F., Finan, T. M., Long, S. R., Puhler, A., Abola, P., Ampe, F., Barloy-Hubler, F., Barnett, M. J., Becker, A. \& other authors (2001). The composite genome of the legume symbiont Sinorhizobium meliloti. Science 293, 668-672.

Giaever, H. M., Styrvold, O. B., Kaasen, I. \& Strom, A. R. (1988). Biochemical and genetic characterization of osmoregulatory trehalose synthesis in Escherichia coli. J Bacteriol 170, 2841-2849.

Gouffi, K., Pichereau, V., Rolland, J. P., Thomas, D., Bernard, T. \& Blanco, C. (1998). Sucrose is a nonaccumulated osmoprotectant in Sinorhizobium meliloti. J Bacteriol 180, 5044-5051.

Gouffi, K., Pica, N., Pichereau, V. \& Blanco, C. (1999). Disaccharides as a new class of nonaccumulated osmoprotectants for Sinorhizobium meliloti. Appl Environ Microbiol 65, 1491-1500.

Hanahan, D. (1983). Studies on transformation of Escherichia coli with plasmids. J Mol Biol 166, 557-580.

Hengge-Aronis, R. (2002). Signal transduction and regulatory mechanisms involved in control of the $\sigma^{\mathrm{S}}$ (RpoS) subunit of RNA polymerase. Microbiol Mol Biol Rev 66, 373-395.

Hengge-Aronis, R., Klein, W., Lange, R., Rimmele, M. \& Boos, W. (1991). Trehalose synthesis genes are controlled by the putative sigma factor encoded by rpoS and are involved in stationary-phase thermotolerance in Escherichia coli. J Bacteriol 173, 7918-7924.

Humann, J. L., Ziemkiewicz, H. T., Yurgel, S. N. \& Kahn, M. L. (2009). Regulatory and DNA repair genes contribute to the desiccation resistance of Sinorhizobium meliloti Rm1021. Appl Environ Microbiol 75, 446-453.

Jebbar, M., Sohn-Bosser, L., Bremer, E., Bernard, T. \& Blanco, C. (2005). Ectoine-induced proteins in Sinorhizobium meliloti include an ectoine ABC-type transporter involved in osmoprotection and ectoine catabolism. J Bacteriol 187, 1293-1304.

Kaasen, I., Falkenberg, P., Styrvold, O. B. \& Strom, A. R. (1992). Molecular cloning and physical mapping of the otsBA genes, which encode the osmoregulatory trehalose pathway of Escherichia coli: evidence that transcription is activated by KatF (AppR). J Bacteriol 174, 889-898.

Kovach, M. E., Elzer, P. H., Hill, D. S., Robertson, G. T., Farris, M. A., Roop, R. M., II \& Peterson, K. M. (1995). Four new derivatives of the broad-host-range cloning vector pBBR1MCS, carrying different antibiotic-resistance cassettes. Gene 166, 175-176.

Kunte, H. J., Crane, R. A., Culham, D. E., Richmond, D. \& Wood, J. M. (1999). Protein ProQ influences osmotic activation of compatible solute transporter ProP in Escherichia coli K-12. J Bacteriol 181, 15371543.

Makihara, F., Tsuzuki, M., Sato, K., Masuda, S., Nagashima, K. V., Abo, M. \& Okubo, A. (2005). Role of trehalose synthesis pathways in salt tolerance mechanism of Rhodobacter sphaeroides $\mathrm{f}$. sp. denitrificans IL106. Arch Microbiol 184, 56-65.

Mclntyre, H. J., Davies, H., Hore, T. A., Miller, S. H., Dufour, J. P. \& Ronson, C. W. (2007). Trehalose biosynthesis in Rhizobium leguminosarum bv. trifolii and its role in desiccation tolerance. Appl Environ Microbiol 73, 3984-3992.

McLeod, S. M., Xu, J. \& Johnson, R. C. (2000). Coactivation of the RpoS-dependent proP P2 promoter by Fis and cyclic AMP receptor protein. J Bacteriol 182, 4180-4187.

Meade, H. M., Long, S. R., Ruvkun, G. B., Brown, S. E. \& Ausubel, F. M. (1982). Physical and genetic characterization of symbiotic and auxotrophic mutants of Rhizobium meliloti induced by transposon Tn5 mutagenesis. J Bacteriol 149, 114-122.
Miller, J. H. (1972). Experiments in Molecular Genetics. Cold Spring Harbor, NY: Cold Spring Harbor Laboratory.

Montero, M., Eydallin, G., Viale, A. M., Almagro, G., Munoz, F. J., Rahimpour, M., Sesma, M. T., Baroja-Fernandez, E. \& PozuetaRomero, J. (2009). Escherichia coli glycogen metabolism is controlled by the PhoP-PhoQ regulatory system at submillimolar environmental $\mathrm{Mg}^{2+}$ concentrations, and is highly interconnected with a wide variety of cellular processes. Biochem J 424, 129-141.

Murphy, H. N., Stewart, G. R., Mischenko, V. V., Apt, A. S., Harris, R., McAlister, M. S., Driscoll, P. C., Young, D. B. \& Robertson, B. D. (2005). The OtsAB pathway is essential for trehalose biosynthesis in Mycobacterium tuberculosis. J Biol Chem 280, 14524-14529.

Pichereau, V., Pocard, J.-A., Hamelin, J., Blanco, C. \& Bernard, T. (1998). Differential effects of dimethylsulfoniopropionate, dimethylsulfonioacetate, and other $S$-methylated compounds on the growth of Sinorhizobium meliloti at low and high osmolarities. Appl Environ Microbiol 64, 1420-1429.

Pinedo, C. A., Bringhurst, R. M. \& Gage, D. J. (2008). Sinorhizobium meliloti mutants lacking phosphotransferase system enzyme HPr or EIIA are altered in diverse processes, including carbon metabolism, cobalt requirements, and succinoglycan production. J Bacteriol 190, 2947-2956.

Roessler, M. \& Müller, V. (2001). Osmoadaptation in Bacteria and Archaea: common principles and differences. Environ Microbiol 3, 743-754.

Sambrook, J., Fritsch, E. F. \& Maniatis, T. (1989). Molecular Cloning: a Laboratory Manual, 2nd edn. Cold Spring Harbor, NY: Cold Spring Harbor Laboratory.

Sauviac, L., Philippe, H., Phok, K. \& Bruand, C. (2007). An extracytoplasmic function sigma factor acts as a general stress response regulator in Sinorhizobium meliloti. J Bacteriol 189, 42044216.

Schafer, A., Tauch, A., Jager, W., Kalinowski, J., Thierbach, G. \& Puhler, A. (1994). Small mobilizable multi-purpose cloning vectors derived from the Escherichia coli plasmids pK18 and pK19: selection of defined deletions in the chromosome of Corynebacterium glutamicum. Gene 145, 69-73.

Seto, A., Yoshijima, H., Toyomasu, K., Ogawa, H. O., Kakuta, H., Hosono, K., Ueda, K. \& Beppu, T. (2004). Effective extracellular trehalose production by Cellulosimicrobium cellulans. Appl Microbiol Biotechnol 64, 794-799.

Singer, M. A. \& Lindquist, S. (1998). Multiple effects of trehalose on protein folding in vitro and in vivo. Mol Cell 1, 639-648.

Sleator, R. D. \& Hill, C. (2002). Bacterial osmoadaptation: the role of osmolytes in bacterial stress and virulence. FEMS Microbiol Rev 26, 49-71.

Smith, L. T. \& Smith, G. M. (1989). An osmoregulated dipeptide in stressed Rhizobium meliloti. J Bacteriol 171, 4714-4717.

Streeter, J. G. (1985). Accumulation of $\alpha, \alpha$-trehalose by Rhizobium bacteria and bacteroids. J Bacteriol 164, 78-84.

Streeter, J. G. \& Bhagwat, A. (1999). Biosynthesis of trehalose from maltooligosaccharides in rhizobia. Can J Microbiol 45, 716-721.

Streeter, J. G. \& Gomez, M. L. (2006). Three enzymes for trehalose synthesis in Bradyrhizobium cultured bacteria and in bacteroids from soybean nodules. Appl Environ Microbiol 72, 4250-4255.

Talibart, R., Jebbar, M., Gouesbet, G., Himdi-Kabbab, S., Wróblewski, H., Blanco, C. \& Bernard, T. (1994). Osmoadaptation in rhizobia: ectoine-induced salt tolerance. J Bacteriol 176, 5210-5217.

Talibart, R., Jebbar, M., Gouffi, K., Pichereau, V., Gouesbet, G., Blanco, C., Bernard, T. \& Pocard, J. (1997). Transient accumulation of glycine betaine and dynamics of endogenous osmolytes in salt- 
stressed cultures of Sinorhizobium meliloti. Appl Environ Microbiol 63, 4657-4663.

Tavernier, P., Besson, I. I., Portais, J. C., Courtois, J., Courtois, B. \& Barbotin, J. N. (1998). In vivo ${ }^{13} \mathrm{C}$-NMR studies of polymer synthesis in Rhizobium meliloti M5N1 strain. Biotechnol Bioeng 58, 250-253.

Vriezen, J. A., de Bruijn, F. J. \& Nusslein, K. (2007). Responses of rhizobia to desiccation in relation to osmotic stress, oxygen, and temperature. Appl Environ Microbiol 73, 3451-3459.

Wolf, A., Krämer, R. \& Morbach, S. (2003). Three pathways for trehalose metabolism in Corynebacterium glutamicum ATCC13032 and their significance in response to osmotic stress. Mol Microbiol 49, 1119-1134.

Yancey, P. H. (2005). Organic osmolytes as compatible, metabolic and counteracting cytoprotectants in high osmolarity and other stresses. J Exp Biol 208, 2819-2830.

Yancey, P. H., Clark, M. E., Hand, S. C., Bowlus, R. D. \& Somero, G. N. (1982). Living with water stress: evolution of osmolyte systems. Science 217, 1214-1222.

Edited by: M. S. B. Paget 